\title{
Ultra-High-speed Micro Machined Surface Integrity of Plastic Strain in Magnetic Abrasive Machining
}

\author{
Rui Wang, Joo Hyun Park, Lida Heng, Jae Won Choi, and Sang Don Mun
}

\begin{abstract}
An ultra-high-speed micro machining process is a micro-machining technique, which is used to minimize the surface roughness and change the precision morphology of the difficult-to-machined materials. Surface integrity is a very important process, which is used to evaluate the highly stress and the loaded components. It is important to evaluate the plastically deformed layers in the precision machined surface process. However, the typical plastic strains in the precision machined surface are significantly difficult to measure. In this paper, the ultra-high-speed micro machining equipment and the critical magnetic abrasive tool were applied in magnetic abrasive machining process. SUS 304 bars which are widely used in many applications were used as the cylindrical workpiece. The aim of this research is to explore a new technique for measuring the plastic strain in magnetic abrasive machining process and for investigating the effects of ultra-high-speed micro machined surface on the plastic strains and strain energy and to determine the residual strain in plastically deformed materials by analyzing the plastically deformed layer. The results concluded that the best improvements in the precision dimensional accuracy and precision surface accuracy were achieved at the ultra-high-speed of $80000 \mathrm{~min}^{-1}$ and the ultra-high-speed machining was not caused the impact of plastically deformed.
\end{abstract}

Index Terms-Ultra-high-speed, magnetic abrasive machining, recrystallization technique, surface integrity, plastic strain, surface accuracy, dimensional accuracy.

\section{INTRODUCTION}

There are many techniques are widely used to improve the surface quality of material. Cutting, grinding, finishing, horning, machining, and cold-drawn techniques have been employed to improve the precision machining of material. However, such mechanical techniques have certain limitations regarding micro-diameter, surface accuracy, dimensional accuracy and processing time. In previous year, some new ultra-precision machining technologies have been developed to improve the accuracy of materials and the magnetic abrasive finishing is proved to be a good precision process [1]-[8]. However, the magnetic abrasive finishing process can only use to improve the simple surface roughness of materials. In this study, the precision machining process is developed with the aim to improve the accuracy of material, such as surface accuracy, dimensional accuracy, and weight

Manuscript received November 20, 2016; revised April 8, 2017. This work was supported by a research program of the national research foundation (NRF) of Korea research in 2014. (Research Project NO. 2014R1A1A2059389).

The authors are with the Mechanical Design Engineering Department, Chonbuk National University, 664-14, Duckjin-gu, Jeonju, South Korea, 561-756 (e-mail: wangruiaa@hotmail.com, henglida1@gmail.com, msd@jbnu.ac.kr). of material, simultaneously. In magnetic abrasive machining technique, the machining process efficiency can be improved by increasing the workpiece revolution speed [9]. The SUS 304 bars, which are widely used in medical devices, nuclear industries and medical enterprise, were used as the cylindrical workpiece. To ensure a great reliability of sensitive components, the surface integrity of SUS 304 alloys should be satisfied. In this study, a difficult-to-machined SUS 304 bar which had been ground by a centerless grinder was machined further using a magnetic abrasive machining process, the feasibility of the concept was demonstrated at a workpiece revolution rate of $80000 \mathrm{~min}^{-1}$. Ultra-high-speed micro processing is well known due to its short machining time and the high machining capability. The plastically deformed layer in a machined surface affects the mechanical properties of machine components, such as fatigue strength, dimensional instability, and stress corrosion cracking. Therefore these properties are called surface integrity. After the ultra-high-speed processing, taking into consideration of those plastically deformed layer affects the machined precision surface, must be considered in precision machining [10]. The analysis of the machined precision surface, including the plastic deformation and strain distribution is carried out and then the micro-diameter change, surface roughness and weight change were analyzed.

\section{EXPERIMENTAL METHOD}

\section{A. Ultra-High-Speed Magnetic Abrasive Machining (MAM) for SUS 304 Bar}

An ultra-high-speed magnetic abrasive machining process shown in Fig. 1 is composed of an ultra-high-speed spindle, cylindrical workpiece, SS41 steel york, several permanent magnets, and magnetic poles. The SUS 304 bar is mounted by the collet chuck of the ultra-high-speed spindle. The machining part is consists of the magnetic pole, permanent magnets, and unbonded magnetic abrasive tools [11]. The unbonded magnetic abrasive tools are supplied between the $\mathrm{N}$-pole and the S-pole and a SUS 304 cylindrical workpiece is inserted inside the magnetic brush and then rotated at an ultra-high-speed. It is possible to apply vibrational action in the linear action direction. Here, have a distance between the workpiece and the magnetic pole, where the magnetic force can be exerted. In addition, a york part is added to induce continuous flow of the magnetic field at the same time.

Fig. 2 shows a photograph of an ultra-high-speed magnetic abrasive machining equipment, which consists of an ultra-high speed spindle, SS41 steel york, cylindrical workpiece, magnet, and electromotive slider. Austenitic 
stainless steel bars (304 stainless steel, $\Phi 30 \times 50 \mathrm{~mm} ; 0.32 \mu \mathrm{m}$ $\mathrm{Ra}$ initial surface roughness) were prepared as cylindrical workpieces for this study. The workpiece was mounted on the ultra-high-speed spindle (speed range: 1000 - $80000 \mathrm{~mm}-1$ ), and magnetic abrasive of unbonded type were insert into the machined area. The workpiece was rotated at an ultra-high-speed and was subject to vibrational motion by placing the magnetic poles close to the workpiece by using an electromotive liner slider control.

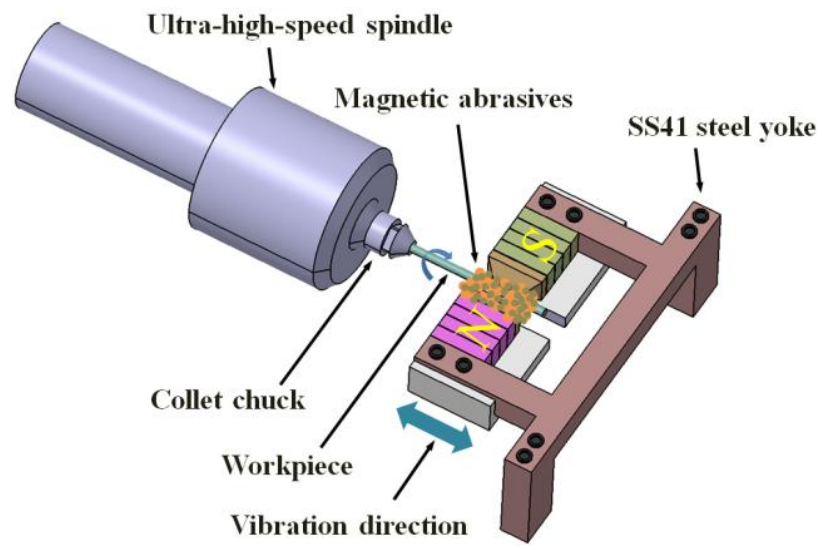

Fig. 1. Principle of ultra-high-speed magnetic abrasive machining.

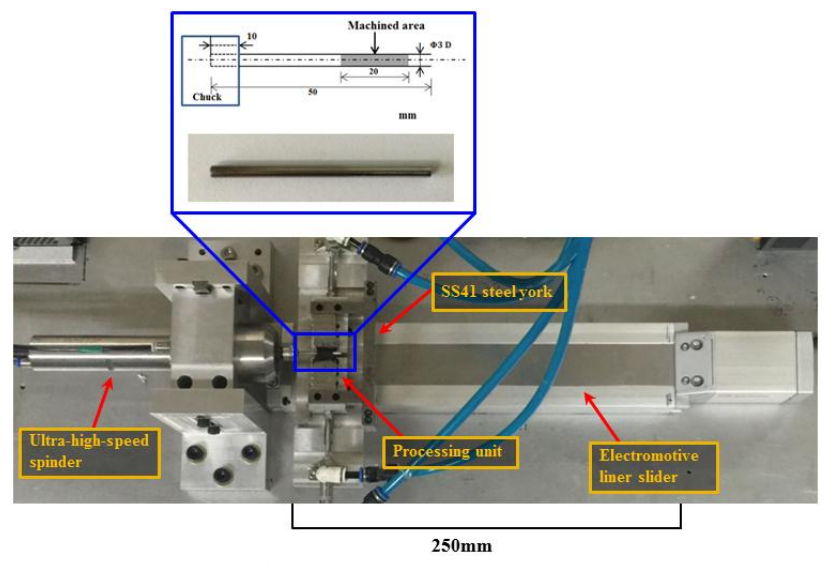

Fig. 2. Schematic of machining process apparatus with workpiece.

\section{B. Surface Integrity for Machining Surface of SUS 304 Bar}

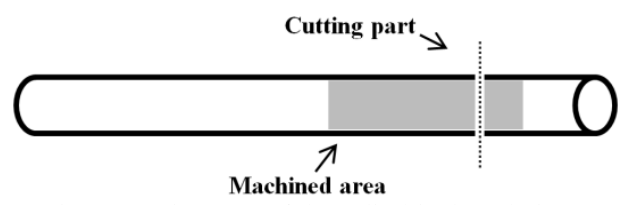

Fig. 3. Cutting area of the cylindrical workpiece.

In this experimental work, the strain measurement is measured by using the recrystallization phenomena method in metals, and then applied to the ultra-high-speed micro machined surface plastic zone. The subsequent recrystallizations method for strain measurement is localized deformed zone, and has been used to measure the surface of plastic strain before and after machining. Fig. 3 shows the machined surface area of the workpiece. In order to avoid the plastic deformation near the surface, the machined surface area of workpiece was cut off by an electric discharge wire cutting machine. The cutting workpiece was used for anneal (recrystallization temperature $950{ }^{\circ} \mathrm{C}$ for $24 \mathrm{~h}$ ) to observe the plastic zone, mechanically polished and then etched in a chemical etchant $\left(\mathrm{C}_{2} \mathrm{H}_{5} \mathrm{OH}\right.$ : HCL: $\left.\mathrm{HNO}_{3}=100: 15: 30\right)$ to observe the recrystallized zone.

The fatigue cracks usually nucleate on the surface, so the condition of the surface plays a major role in the fatigue resistance of a component. Therefore, the fatigue strength is often varied greatly depending on the surface condition of the material. The fatigue failure of material is started from the deteriorated surface roughness of material. Thus, the ultra-high precision magnetic abrasive machining process is required for improving surface roughness of material and tensile strength. Fig. 4 shows the effects of the surface finish on fatigue endurance limit. In previous study, many researchers have studied the surface finish effects on fatigue endurance limit [12]. It was confirmed that the polishing process is the most processing method to enhance the fatigue limit of the materials, but only emphasized the traditional mirror polishing processing. In this study, the ultra-high-speed magnetic abrasive machining processing was applied for machining surface of material and to study the effects of this method on the improvement on the surface roughness and the tensile strength of material with the short processing time and then assesses the machining capabilities for application to improve the life of materials.

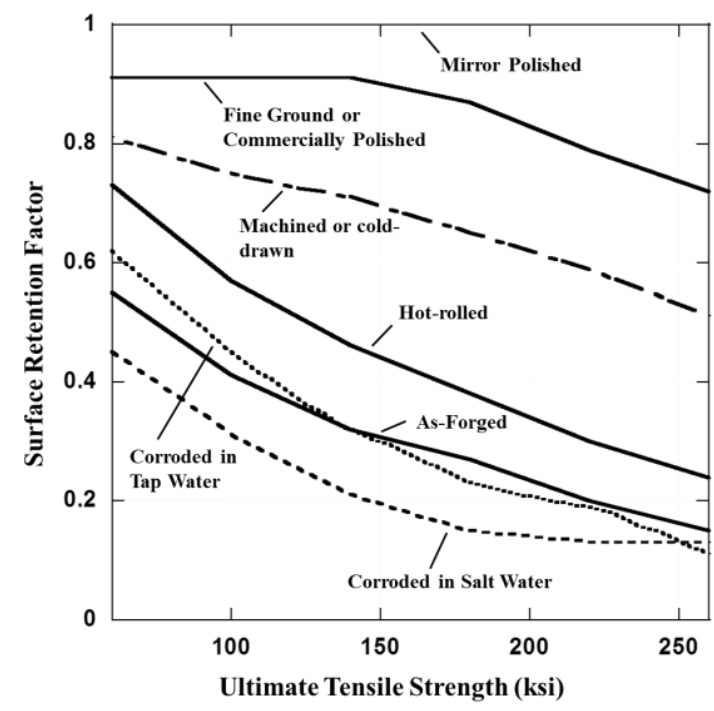

Fig. 4. Surface finish effects on fatigue endurance limit [12].

\section{EXPERIMENTAL CONDITIONS}

Table I show the experimental conditions used in ultra-high-speed micro machining process. Table II shows the material characteristics of 304 stainless steel bar.

TABLE I: EXPERIMENTAL CONDITIONS

\begin{tabular}{ll}
\hline \hline Workpiece & 304 stainless steel bar $(\Phi 3 \times 50 \mathrm{~mm})$ \\
\hline Workpiece revolution & $80000 \mathrm{~min}^{-1}$ \\
Workpiece pole tip clearance & $1 \mathrm{~mm}$ \\
Lubricant & Light oil, $0.1 \mathrm{ml}$ \\
& $\left(\mathrm{pH}: 9.5\right.$, viscosity: $755 \mathrm{MPa}$ s at $\left.26^{\circ} \mathrm{C}\right)$ \\
Magnetic tool & Iron particles: $200 \mu \mathrm{m}, 70 \mathrm{mg}$ \\
& Diamond paste: $0.5 \mu \mathrm{m}, 10 \mathrm{mg}$ \\
Magnetic flux density & $0.52 \mathrm{~T}$ \\
Magnetic pole vibration & $10 \mathrm{~Hz}$ \\
Magnetic type & $\mathrm{Nd}-\mathrm{Fe}-\mathrm{B}$ permanent magnetic \\
Machining time & $0-120 \mathrm{sec}$ \\
\hline \hline
\end{tabular}


TABLE II: MATERIAL CHARACTERISTICS OF 304 STAINLESS STEELS

\begin{tabular}{ll}
\hline \hline Young's modulus & $201 \mathrm{GPa}$ \\
\hline Poisson's ratio & 0.3 \\
Yield strength & At $30^{\circ} \mathrm{C}, 205 \mathrm{GPa}$ \\
Ultimate tensile strength & $515 \mathrm{MPa}$ \\
Allowable stress & At $30{ }^{\circ} \mathrm{C}, 183 \mathrm{MPa}$ \\
Thermal expansion coefficient & $1.33 \mathrm{E}-05$ \\
Thermal conductivity & $14.8 \mathrm{~W} / \mathrm{Mk}$ \\
Specific heat & $480 \mathrm{~J} / \mathrm{kgK}$ \\
Mass density & $7900 \mathrm{Kg} / \mathrm{m}^{3}$ \\
\hline \hline
\end{tabular}

\section{EXPERIMENTAL RESULTS AND DISCUSSION}

Fig. 5 shows the largely linear relationship between the change of diameter and material removal against the machining time. The workpiece was rotated at $80000 \mathrm{~min}^{-1}$. Magnetic poles were vibrated at $10 \mathrm{~Hz}$. In the case of change of diameter, it was shown that the ultra-high precision magnetic abrasive machining process can remove 5 - $\mu \mathrm{m}$ from diameter of workpiece with every 20 seconds, which the current processing methods are impossible. The slop of material removal shows the constant removal pattern due to the usage of same grain size of iron particle and diamond particle.

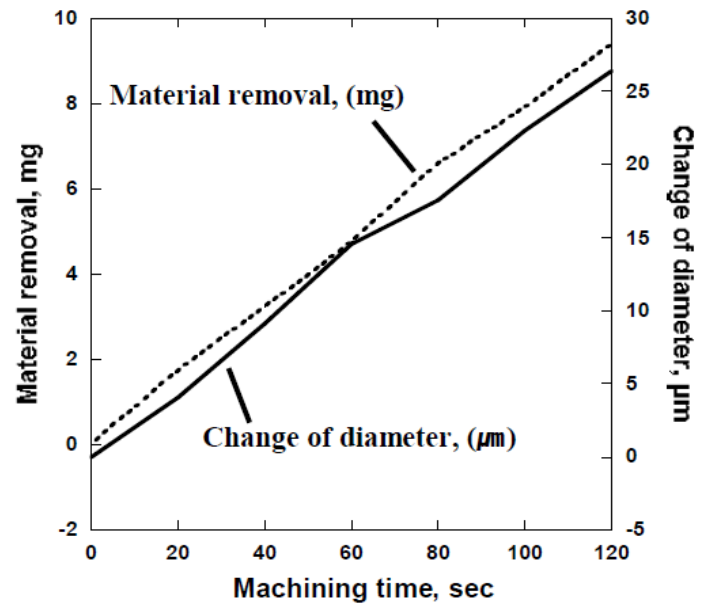

Fig. 5. The change of diameter and material removal weight against the machining time at $80000 \mathrm{~min}^{-1}$.

Fig. 6 shows the relationship between the surface roughness (arithmetical average roughness, $\mathrm{Ra}$ ) and the machining time. The workpiece was rotated at $80000 \mathrm{~min}^{-1}$. Magnetic poles were vibrated at $10 \mathrm{~Hz}$. The surface roughness was rapidly improved from the initial machining time at $0 \mathrm{sec}$ to the machining time at 20 seconds. The initial surface roughness Ra was improved from $0.32 \mu \mathrm{m}$ to $0.04 \mu \mathrm{m}$ for $20 \mathrm{sec}$. After $40 \mathrm{sec}$, the initial surface roughness was improved to $0.03 \mu \mathrm{m}$. It can be confirmed that, for improving the value surface roughness ( $\mathrm{Ra}$ ) of workpiece, the ultra-high-speed machining processing is required 40 seconds to achieve the most perfect state of surface roughness. Fig. 7 shows the AFM images of the surface roughness before and after machining with ultra-high-speed magnetic abrasive machining at $80000 \mathrm{~min}^{-1}$. As shown in Fig. 7(a) that before machining, many scratches and deep grooves could be seen everywhere throughout the surface of the material. Fig. 7(b) shows the AFM image of a workpiece after machining with a Ra value of $0.03 \mu \mathrm{m}$ at $80000 \mathrm{~min}^{-1}$ for 40 seconds. As shown in the Fig. 7(b) that the scratches and deep grooves were completely removed from the machined surface.

Fig. 8 shows the annealed microstructure on the cutting surface of the workpiece after machining by the ultra-high-speed precision machining process. In the process, the plastically deformed zones at the machining tip increases with machining depth. The recrystallized grain size in the primary deformation zone after anneal is smaller than the surrounding region. This indicates that the primary deformation zone is deformed. The micrographs is shown in Fig. 9(b), the strain distribution around the machining surface cannot be drawn before machining. As show in Fig. 9(a) and 9(b) before and after machining, the isotropic shape of microstructure is not changed. It indicates that the ultra-high-speed machining process is not effects on the plastically deformed.

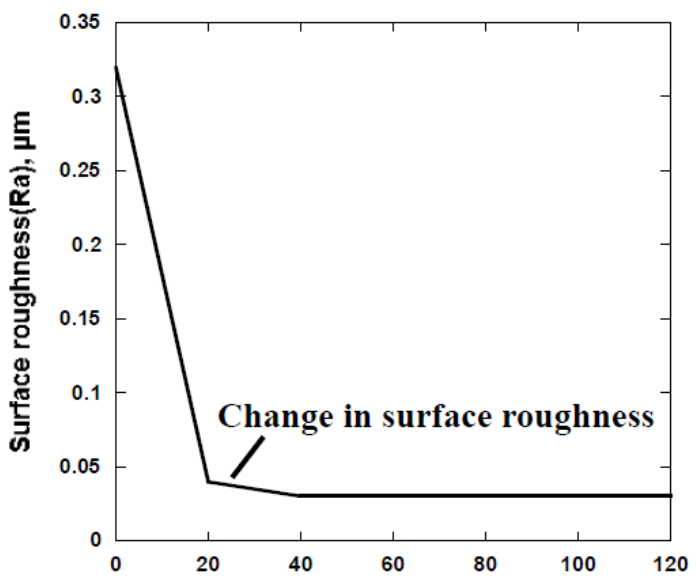

Fig. 6. Variations in surface roughness vs. machining time at $80000 \mathrm{~min}^{-1}$.

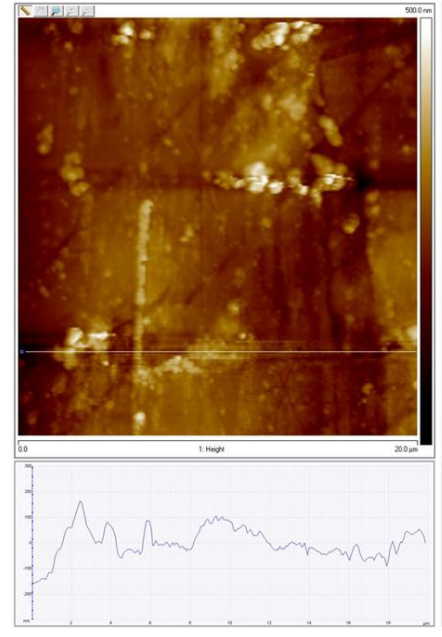

(a) Before machining

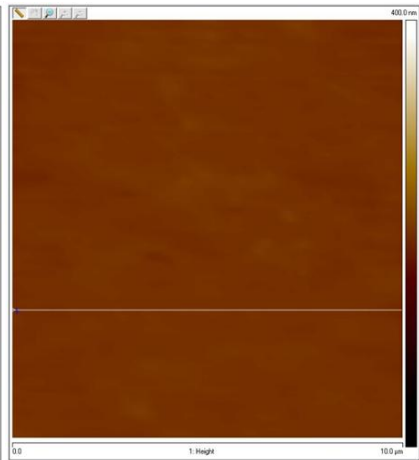

Fig. 7. AFM images of surface conditions prior to and after machined by ultra-high-speed magnetic abrasive machining with $80000 \mathrm{~min}^{-1}$.

The surface modification factor can be expressed by Eq. (1)

$$
K s=a S_{u}^{b}
$$

where $K s$ is the surface modification factor, $S_{u}$ is the ultimate tensile strength, and $(a, b)$ are constants. The value of Ks can be calculated by using the value of $(a, b)$. The value of $a$, and $b$ before machining are given as $515 \mathrm{MPa}$ and 0.3 , respectively (as shown in Fig. 4). The surface modification factor has an increase as the increasing of tensile strength or 
hardness. When the surface roughness improved from $0.32 \mu \mathrm{m}$ to $0.03 \mu \mathrm{m}$, the fatigue limit value increases and the material life also improve.

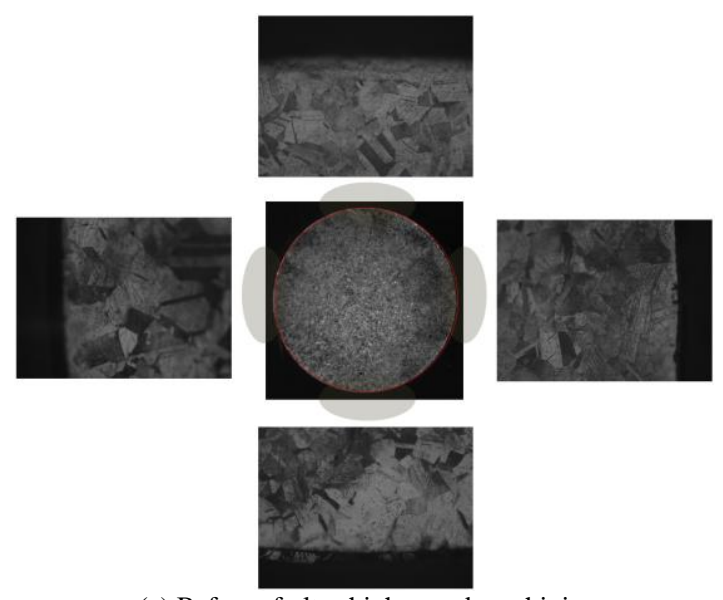

(a) Before of ultra-high-speed machining
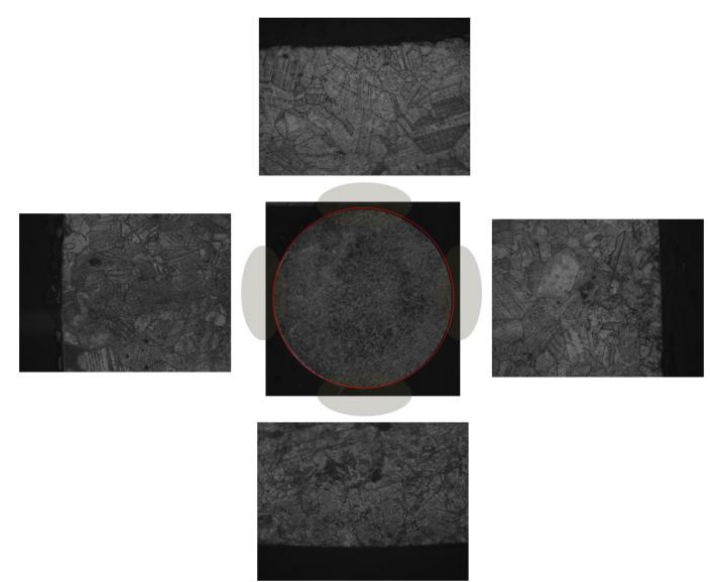

(b) After of ultra-high-speed machining

Fig. 8. Recrystallized microstructures showing plastic deformation zone with recrystallization temperature $950^{\circ} \mathrm{C}$ for $24 \mathrm{~h}$.

\section{CONCLUSION}

The results of this research can be summarized as follows:

1) An $80000 \mathrm{~min}^{-1}$ of ultra-high-speed micro machining process was achieved for difficult-to-machined materials SUS 304.

2) The best improvements in the precision dimensional accuracy and precision surface accuracy were achieved at the ultra-high-speed of $80000 \mathrm{~min}^{-1}$. In the case of change of diameter, the ultra-high precision magnetic abrasive machining process can remove $5-\mu \mathrm{m}$ from the diameter of workpiece with every 20 seconds. In the case of material removal, the slope showed the constant removal pattern due to the usage of same grain size of iron particle and diamond particle. In the case of surface roughness, it requires $40 \mathrm{sec}$ to improve the surface roughness from $0.32 \mu \mathrm{m}$ to $0.03 \mu \mathrm{m}$

3) The recrystallization technique was applied for measurement of the plastic strain of machined surface. It confirmed that the ultra-high-speed machining was not caused the impact of plastically deformed.

4) The ultra-high-speed magnetic abrasive machining is a processing method which can greatly enhance the fatigue limit of the materials and material life.

\section{ACKNOWLEDGMENT}

This work was supported by a research program of the national research foundation (NRF) of Korea research in 2014, (Research Project No. 2014R1A1A2059389).

\section{REFERENCES}

[1] M. M. Ridha, Y. H. Zou, and S. Hitoshi, "Development of a new internal finishing of tube by magnetic abrasive finishing process combined with electrochemical machining," International Journal of Mechanical Engineering and Applications, vol. 3, no. 2, pp. 22-29, 2015.

[2] Y. M. Baron, "Improvement of wearing and hardening using magnetic field," Create Space Independent Publishing Platform, Saint-Petersburg.

[3] M. Fox, K. Agrawal, T. Shinmura, and R. Komanduri, "Magnetic abrasive finishing of rollers," Annals of the CIRP, vol. 43, no. 1, pp. 181-184, 1994.

[4] J. Kang and H. Yamaguchi, "Internal finishing of capillary tubes by magnetic abrasive finishing using a multiple pole-tip system," Precision Engineering, vol. 36, pp. 510-516, 2012.

[5] S.-D. Mun, "Micro machining of high-hardness materials using magnetic abrasive grains," International Journal of Precision Engineering and Manufacturing, vol. 11, no. 5, pp. 763-770, 2010.

[6] J. Z. Wu, Y. H. Zou and H. sugiyama, "Study on ultra-precision magnetic abrasive finishing process using low frequency alternation magnetic field," Journal of Magnetism and Magnetic Materials, vol. 386, pp. 50-59, 2015.

[7] H. Yamaguchi, A. K. Srivastava, M. Tan, and F. Hashimoto, "Magnetic abrasive finishing of cutting tools for high-speed machining of titanium alloys," vol. 7, pp. 299-304, 2014.

[8] G. A. Ibrahim, C. H. C. Haron, and J. A. Ghani, "Tool wear mechanism in continuous cutting of difficult-to-cut material under dry machining," Trans. Tech. Publications, pp. 126-128, 2012.

[9] J. Kang, A. George, and H. Yamaguchi, "High-speed internal finishing of capillary tubes by magnetic abrasive finishing," Procedia CIRP 1 , pp. 414-418, 2012

[10] Y. Lino, T. Y. Kim, and S. D. Mun, "Machined surface plastic strain in orthogonal cutting by subsequent recrystallization technique," Wear, vol. 199, pp. 211-216, 1996.

[11] I.-T. Im, S. D. Mun and S. M. Oh, "Micro machining of an STS 304 bar by magnetic abrasive finishing," Journal of Mechanical Science and Technology, vol. 23, pp. 1982-1988, 2009.

[12] S. A. McKelvey and A. Fatemi, "Surface finish effect on fatigue behavior of forged steel," International Journal of Fatigue, vol. 36, pp. 130-145, 2012.

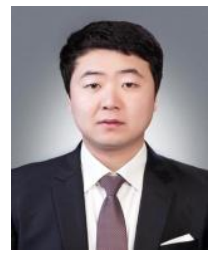

Rui Wang received the B.S and M.S. in mechanical design engineering from Chonbuk National University, Korea, in 2013 and 2015, respectively. He is currently a Ph.D. student in mechanical design engineering at Chonbuk National University. His research interests include ultra-precision machining and mechanical machining.

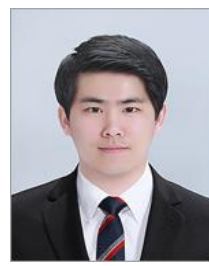

Joo Hyun Park received the B.S in mechanical design engineering from Chonbuk National University, Korea, in 2016. He is currently a M.S student in mechanical design engineering at Chonbuk National University. His research interests include ultra-precision machining and mechanical machining.

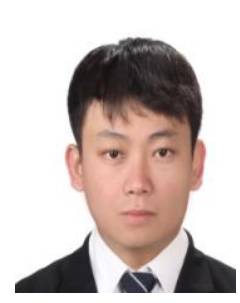

Lida Heng received his B.S. degree in Department of Mechanical and Automotive Engineering from Jeonju University, Korea in 2014 and M.S. in Precision Mechanical Engineering from Chonbuk National University, Korea, in 2015. He is currently a Ph.D. student at Division of Mechanical Design Engineering at Chonbuk National University, Korea His research interests include Ultra-precision machining and mechanical machining. 


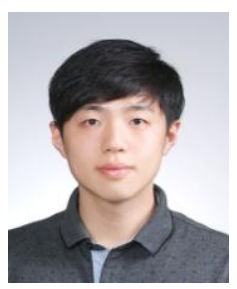

Jae Won Choi received the B.S degree in Mechanical Design Engineering from Chonbuk National University, Korea, in 2016. He is a currently B.S. student in mechanical design engineering at Chonbuk National University. His research interests include ultra-precision machining and mechanical machining.

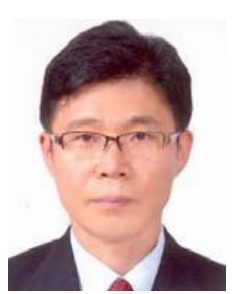

Sang Don Mun received the B.S. degree and M.S. in Precision Mechanical Engineering from Chonbuk National University, Korea, in 1991 and 1993 , respectively. He then received the Ph.D. in Precision Mechanical Engineering at the same university in 1997. Dr. Mun is currently a Professor at the Division of Mechanical Design Engineering at Chonbuk National University in Jeonju, Korea. His research interests include magnetic abrasive finishing, tool wear, and micro machining. 